\title{
Museu virtual do Instituto de Física da Universidade Federal do Rio de Janeiro: virtualidade, memória e museu
}

\author{
Virtual Museum of the Physics Institute of the Federal University of Rio de Janeiro: virtuali- \\ ty, memory and museum
}

\author{
Robson da Silva Teixeira \\ Doutorando em Museologia e Patrimônio \\ Universidade Federal do Estado do Rio de Janeiro \\ teixeira@if.ufrj.br
}

\begin{abstract}
Resumo
O estudo analisou as questões que envolvem o Museu Virtual do Instituto de Física da Universidade Federal do Rio de Janeiro (IF UFRJ), um espaço cibernético voltado para a memória institucional do IF UFRJ, que em 2021 faz 57 anos, e ocupa um lugar de destaque entre as instituições de ensino e pesquisa no Brasil. Dentro deste quadro, as metas foram atualizar e revisar os tópicos que compõem a ferramenta de disseminação da informação; ou seja, a inclusão de fotos do Professor Fundador Plínio Sussekind Rocha e da Professora Sarah de Castro Barbosa no tópico Fotografias; organização de conteúdo para o tópico Levantamento documental e elaboração de um termo de consentimento, denominado carta de autorização para o tópico história oral, que é composto por entrevistas com os Professores Eméritos e ex-alunos da Instituição. Para cumprir este propósito, a metodologia da pesquisa foi dividida em etapas: elaboração de pesquisa iconográfica para coletar fotografias; levantamento documental com o intuito de coletar documentos que abordavam o Instituto e seus Professores Fundadores; e entrevista-narrativa com os Professores Eméritos e Ex-alunos do IF UFRJ Erasmo Madureira Ferreira, Fernando de Souza Barros, Herch Moysés Nussenzveig, Nelson Velho de Castro Faria, Nicim Zagury, Takeshi Kodama, Leandro Salazar e Máximo Ferreira da Silveira. Para a realização desta última etapa foi necessário a elaboração de um instrumento para coleta de dados, uma carta de autorização que permite a disseminação das informações recuperadas através das entrevistas. A coleta de dados ocorreu no período de junho a dezembro de 2018. Concluí-se que o serviço online está atualizado, com conteúdo revisado e dentro dos padrões; o Museu Virtual do IF UFRJ é um patrimônio cultural científico que cumpre o seu papel de preservar e disseminar informação fazendo com que a unidade de informação busque realizar um trabalho ligado aos interesses da comunidade científica, onde ela participa, interroga e descobre valores, além de poupar o tempo do usuário, através da otimização do serviço.
\end{abstract}

\section{Palavras-Chave}

Museu virtual. Memória institucional. Biblioteca universitária. Universidade Federal do Rio de Janeiro (UFRJ).

\begin{abstract}
The study analyzes the issues involving the Virtual Museum of the Institute of Physics of the Federal University of Rio de Janeiro (IF UFRJ), a cyberspace focused on the institutional memory of IF UFRJ, which in 2021 turns 57, and occupies a prominent place among teaching and research institutions in Brazil. Within this framework, the goals were to update and review the topics that make up the information dissemination tool; that is, the inclusion of photos of Founding Professor Pliny Sussekind Rocha and Professor Sarah de Castro Barbosa in the topic Photos; content organization for the topic Documentary survey and preparation of a consent form, called authorization letter for the topic oral
\end{abstract}


history, which consists of interviews with professors emeritus and former students of the institution. To fulfill this purpose, the research methodology was divided into stages: preparation of iconographic research to collect photographs; documentary survey in order to collect documents that addressed the Institute and its Founding Professors; and narrative interview with Professors Emeritus and Alumni of IF UFRJ Erasmo Madureira Ferreira, Fernando de Souza Barros, Herch Moysés Nussenzveig, Nelson Velho de Castro Faria, Nicim Zagury, Takeshi Kodama, Leandro Salazar and Máximo Ferreira da Silveira. To perform this last stage, it was necessary to develop an instrument for data collection, a letter of authorization that allows the dissemination of the information retrieved through the interviews. Data were collected from June to December 2018. It was concluded that the online service is up-to-date, with content reviewed and within the standards; the Virtual Museum of IF UFRJ is a scientific cultural heritage that fulfills its role of preserving and disseminating information by making the information unit seek to carry out work related to the interests of the scientific community, where it participates, interrogates and discovers values, in addition to saving the user's time, through the optimization of the service.

\section{Keywords}

Virtual museum. Institutional memory. University library. Federal University of Rio de Janeiro (UFRJ).

\section{INTRODUÇÃO}

Fornecendo histórico do serviço online, destaca-se que o museu Virtual do Instituto de Física da Universidade Federal do Rio de Janeiro - IF UFRJ, um instrumento para disseminação da informação foi criado em 2014. Ele é um link dentro do site da Biblioteca do Instituto de Física ${ }^{1}$. E tem como objetivo preservar e disseminar a memória e história da Instituição e dos professores que fizeram parte dela. $O$ espaço cibernético foi criado com a intenção de facilitar o processo de busca de informação, assim como viabilizar um espaço colaborativo de informação e conhecimento voltados para a comunidade acadêmica da Física e áreas afins.

O Instituto de Física da Universidade Federal do Rio de Janeiro (IF UFRJ) foi criado em 19 de março de 1964 e faz parte do Centro de Ciências Matemáticas e da Natureza (CCMN) da referida universidade. O IF foi criado por ocasião da reforma universitária, que reuniu os cursos de Física então existentes em escolas e faculdades do Rio de Janeiro pertencentes à então denominada Universidade do Brasil (UNIVERSIDADE FEDERAL DO RIO DE JANEIRO (Brasil), [20--]).

O IF UFRJ é uma entidade que tem uma memória institucional e seus professores são o patrimônio científico da Instituição. Ou seja, os campos do conhecimento registram a presença diversificada de olhares consolidados e novos, de aproximações e afastamentos, de inovações, e de agregações entre outras formas de manifestações do pensar e do agir, a exemplo do caso a ser tratado no presente artigo: as visões e significações emprestadas à Memória Coletiva e ao Patrimônio Cultural em entidade acadêmica brasileira que trata do domínio da Física.

A preservação digital da memória e história a partir de um Museu Virtual do Instituto de Física da Universidade Federal do Rio de Janeiro IF UFRJ, um modelo em ambiente cibernético, que até o momento reúne coleções de objetos (um instrumento científico, fotografias de época, a mesa de reunião para fundação do IF UFRJ, recortes de jornais e revistas, e

\footnotetext{
${ }^{1}$ A biblioteca foi criada em 1967, e em 22 de dezembro de 1981 a Congregação do IF/UFRJ resolveu dar-Ihe o nome do professor Plínio Sussekind Rocha.
} 
outros documentos) ligados à vida da Instituição, isto é, o Patrimônio e a Memória em formato material e imaterial.

O que foi desenvolvido pelos Professores na docência, pesquisa e comunicação científica entre outras atividades acadêmicas formam um conjunto que permite ser identificado como um Patrimônio Cultural da Ciência, melhor dizendo de C\&T, e composto "do legado tangível e intangível" (GRANATO, 2017) de um espaço de produção intelectual.

Deste modo, é um Patrimônio Intelectual que está de acordo com a compreensão da Organização das Nações Unidas para Educação, Ciência e Cultura- UNESCO, dada na sua Convenção para Salvaguarda do Patrimônio Cultural Imaterial, Convention for the Safe guarding of the Intangible Cultural Heritage (2003), que aponta a "profunda interdependência entre o patrimônio cultural imaterial e o patrimônio material cultural e natural".

O produto Museu Virtual do Instituto de Física da UFRJ segue o modelo de Museu Virtual de Composição Mista, tendo como acervo o material produzido e usado pelos pesquisadores, visando por meio de processo de digitalização trazer a público a história da pesquisa praticada pelos professores brasileiros no contexto nacional e internacional.

O referido espaço cibernético tem o objetivo de salvaguardar o Instituto de Física; porém o Museu Virtual não existe no mundo real/físico, mas existe a coleção de documentos diversificados e para a pesquisa científica, esses documentos são considerados itens importantes da história da Instituição.

Entretanto, o Museu Virtual do IF UFRJ, que tem entre seus propósitos ser um espaço para divulgar informação especializada sobre a pesquisa, o ensino e as realizações acadêmicas da Física no Brasil bem como da sua presença no cenário internacional necessita de constantes revisões, atualizações e inclusão de novos documentos.

A ideia de desenvolver um Museu Virtual do Instituto de Física da Universidade Federal do Rio de Janeiro (IF UFRJ) surgiu a partir do questionamento dos usuários sobre a capacidade do Serviço de Referência de uma Biblioteca Universitária em atender de forma satisfatória às suas necessidades. A partir desse questionamento e da constatação de que a Unidade de Informação necessitava de canais mais dinâmicos e atuais para disseminação da informação, surgiu à necessidade de desenvolver a página do Museu Virtual.

Fato comprovado pela pesquisa de Teixeira (2018, p. 178), que no primeiro semestre de 2018 elaborou uma pesquisa com 176 usuários sobre a aplicabilidade do museu virtual da instituição. A partir desta pesquisa de avaliação chegou-se a alguns resultados que demandam ações a serem implantadas para otimizar o serviço online, pois o conteúdo foi considerado relevante pela comunidade, o que motivou o engajamento da equipe para a reorganização e atualização do Museu Virtual do IF/UFRJ (TEIXEIRA, 2018, p. 178).

Os resultados da pesquisa permitiram concluir que independente de o Museu Virtual do IF/UFRJ ter seis anos de implementação, ainda há muito trabalho a ser realizado. Ele necessita de constantes revisões, ajustes e atualizações, pois alguns dos conteúdos do site foram considerados incipientes e carecem de inclusão de informações ou uma melhor apresentação (TEIXEIRA, 2018, p. 178).

O artigo aponta uma problemática contemporânea a respeito da virtualidade nos museus e a organização de conteúdo dos acervos materiais e virtuais. Para tanto indagou-se: quais os tópicos do Museu virtual necessitam de atualização e inclusão de imagem, fotografias e informação?

A Justificativa relevante para a questão proposta é o surgimento dos Museus Virtuais como ferramenta para salvaguarda da Memória Institucional. Percebe-se que o desenvolvimento e a globalização das redes virtuais permitem visualizar outra dimensão da 
memória: a memória que nasce da correspondência entre o real e a virtualidade imagética. Scheiner (1998) crê que vivemos hoje em dia num universo visual, onde a força mágica das imagens nos dá a ilusão de que o real é o que vemos diante de nós, porém o mundo imagético se cria fora das ordens simbólicas, que se tornam, elas mesmas, grandes peças de museu.

Segundo Scheiner (1998), a imagem nos dá, assim, a ideia de ser senhor de nossas próprias lembranças: a memória torna-se uma memória desejada, esperada, manipulada pelo indivíduo. Para a autora, este é o museu virtual, onde o homem é simultaneamente criador e criatura do seu próprio caleidoscópio de representações (SCHEINER, 1998).

A coleção de Ciência e Tecnologia (C\&T) do IF/UFRJ tomada como "objeto musealizado" foi incorporada ao Museu Virtual do IF/UFRJ, para que possa desempenhar o seu papel de comunicação e informação em Museologia, através do seu poder simbólico; pois a Teoria Museológica vem permitindo compreender "o caráter fenomênico do Museu e sua capacidade de manifestar-se de diferentes maneiras, no tempo e no espaço, para além das formas instituídas e/ou já reconhecidas" (SCHEINER, 1998, P. 89). Ressalta-se que a presente pesquisa justificou também a própria existência do Museu Virtual do IF/UFRJ, pois a sua coleção tomada como "objeto de museu" cumpre o papel de ser um instrumento de comunicação e divulgação científica.

Pelo exposto, o presente artigo tem como objetivo atualizar e revisar os tópicos que compõem o Museu virtual do IF UFRJ, objetivando assim enquadrá-lo como uma ferramenta de disseminação de informação em consonância com as demandas dos seus usuários. Dentro desta perspectiva, delimitou-se aos seguintes objetivos específicos: incluir fotos dos Professores Fundadores do IF UFRJ no tópico Fotografias; identificar e descrever novos conteúdos no Levantamento documental; apresentar um termo de consentimento para o tópico história oral com professores eméritos e ex-alunos do IF UFRJ (em fase de execução) e elaborar instrumentos para coleta (carta de autorização), análise (tabelas e quadros para o tópico Fotografia) e interpretação dos dados colhidos (reorganização da descrição das matérias do tópico Levantamento Documental); objetivando colocar os tópicos do Museu Virtual nos padrões necessários para uma ferramenta digital de preservação e memória do Campo da Física praticada no Brasil que reverbera no exterior.

\section{CONCEITO DE MUSEU VIRTUAL À LUZ DOS PENSADORES DO CAMPO DA FILOSOFIA, CIÊNCIA DA INFORMAÇÃO E MUSEOLOGIA}

A fundamentação teórica está balizada na tentativa de diálogo entre as áreas da Filosofia (Virtual/Virtualidade/Virtualização), Ciência da Informação (documentação / disseminação da informação / comunicação científica) e Museologia (memória institucional/patrimônio científico/ musealização / museu virtual), na busca de pontos comuns e interfaces prováveis entre as três Ciências.

Tendo em vista o campo museológico os autores deste domínio do conhecimento, Desvallées e Mairesse (2013, p. 42) definem musealização como "a operação destinada a extrair, física e conceitualmente, uma coisa de seu meio natural ou cultural de origem e darIhe um estatuto museal, transformá-lo em musealium ou museália, [...] fazê-la entrar no campo do museal".

Outro autor do mesmo campo, Zbynek Stránský (1980, p. 33-40), criador da noção de musealidade, a condição específica de algo ou coisa que adquire o estatuto de inserção como objeto tratado pelo Museu, contribui com a argumentação ao afirmar que "a Museologia 
tem a natureza de uma ciência social, proveniente das disciplinas científicas, documentais e mnemônicas [memória] e ela auxilia à compreensão do homem no seio da sociedade".

Ou seja, o olhar museológico está embasado, entre outros autores do campo, em André Desvallées e Francois Mairesse (2013, p. 45) explicando que a Museologia permite, em se tratando do Museu, que seja estudado "em sua história e no seu papel na sociedade, nas suas formas específicas de pesquisa [...], de apresentação, [...] de difusão" [...].

Por este motivo, a musealização, como processo científico, compreende necessariamente o conjunto das atividades que se fazem no museu: preservação, seleção, aquisição, pesquisa, catalogação, indexação e comunicação (DESVALLÉES; MAIRESSE, 2013, p. 58); entendendo-se nesta última a disseminação da informação.

Corroborando com esta afirmação, Loureiro (2012, p.2-3) explica que a musealização é "um conjunto de processos seletivos baseados na agregação de valores a coisas de diferentes naturezas às quais é atribuída a função de documento, e que por esse motivo tornam-se objeto de preservação e divulgação".

A disseminação da informação está associada com a produção, seleção e organização destes documentos, que ao longo do tempo precisam ser conservados, para que seja preservada sua história, onde a busca pelo conhecimento, se faz através de serviços de disseminação da informação em diversos formatos, como por exemplo, os Museus.

Para Lara e Conti:

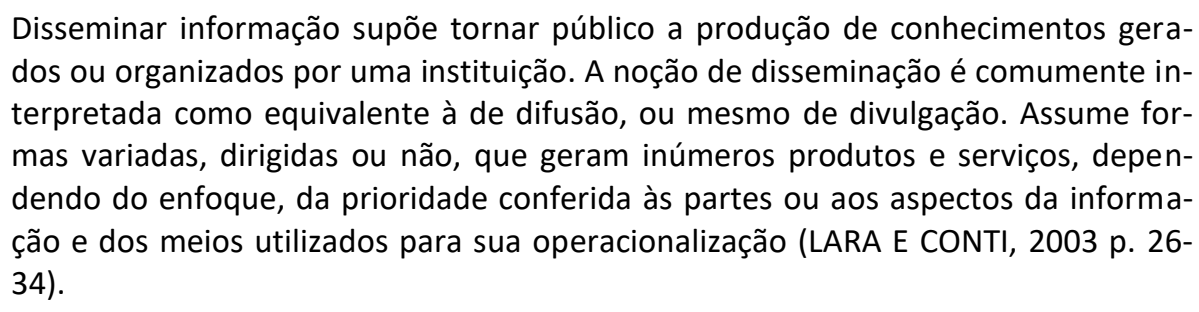

Portanto, toda a história do Instituto de Física da UFRJ - desde o espaço físico que ocupa, do conceitual que representa, dos físicos e de suas atividades profissionais do pensar teórico até a ação prática nos laboratórios nos leva a pensá-lo com caráter a ser registrado; pois isto é o que, simbolicamente, uma coleção deste teor tem condições de representar, um determinado pensamento de um conjunto de pesquisadores.

Por outro lado, os documentos são a materialização das ideias da Física e apresentam valor histórico para o campo da Física e a pesquisa os tem como documentos que representam a colaboração da produção brasileira em contexto internacional. Paul Otlet (1934. p. 216-217) afirmou nos anos 30 do século passado que a Documentação deve alcançar todas as representações, objetos quando possuidores de "valor documental"; e qualifica o objeto de museu como "substituto do livro", noção que se aplica a quaisquer objetos capazes de atingir "os mesmos objetivos buscados nos livros, isto é, ser um veículo de informação, comunicação" (OTLET, 1934, p.218).

Portanto, no contexto da história do IF UFRJ ao tratar da Memória Institucional e tomar por base para o estudo a pesquisadora IcléiaThiesen Magalhães Costa e pode-se dizer que: "a memória institucional é o reflexo dessa trajetória, não como mimesis, mas um cristal com suas múltiplas e infinitas facetas".

Sendo assim é formada por um conjunto de elementos que a consolida e a define como memórias, entre os quais se destacam: "histórico institucional/local"; "identidade da instituição"; "formação/definição/consolidação da instituição"; e suas "relações sociais" (COSTA, 1997, p. 34), que serão visualizadas hoje e no futuro, contextualizando o passado e 
o presente (COSTA, 1997, p. 34). Tem como característica não ser estática porque se encontra em permanente concepção, sendo instituída diariamente pelos membros do grupo (COSTA, 1997, p. 36). Considera-se a Memória no papel de elemento primordial para o funcionamento das instituições porque é através do seu exercício que as instituições se reproduzem no seio da sociedade, que elaboram informações de interesse à sua atuação, pois a formalização de práticas de preservação e difusão da "memória institucional" é cada vez mais comum nas "sociedades contemporâneas" (COSTA, 1997, p. 38).

Bernard Deloche (2001) trata no seu livro "El museo Virtual" a questão da virtualidade das Imagens e dos Museus, relata o surgimento dos museus virtuais e os debates sobre os museus virtuais como substitutos do museu tradicional. Deloche (2001) relata que a questão dos museus virtuais não foi tratada no livro como termos de existência, realidade ou utopia e sim pelo viés do seu significado. Segundo Deloche (2001), as respostas para essas indagações partem do pressuposto de que não se trata de discutir a chegada de um substituto do museu; mas entender as diferentes manipulações da imagem, como por exemplo, as tentativas de experimentação de espaços inteiramente inventados pelo homem, isto é, os museus virtuais que só existem na web, uma importante reflexão sobre os museus na contemporaneidade.

Por outro lado, Deloche (2001) relata que mesmo considerando o museu virtual como substituto do museu tradicional, ele reconhece que há incompatibilidade entre o museu tradicional e o museu paralelo. $\mathrm{O}$ autor estuda a questão da virtualidade no processo museológico, debruçando-se basicamente sobre os museus de arte, estudando o que ele chama de tripla reciprocidade da arte. Para ele, a arte está ligada a três termos fundamentais: o estético, o museal e o virtual (DELOCHE, 2001).

Para Anna Lisa Tota (2000), os museus virtuais online são na sua maioria, aproximações imperfeitas dos museus físicos. Neste sentido, Pierre Lévy (2000) afirma que o que é comumente chamado de museu virtual nada mais é do que um catálogo na Internet. A questão levantada por Lévy (2000) é importante, na medida em que a discussão sobre os museus virtuais ainda é incipiente. Lévy (2000) relata que os profissionais de museus deveriam discutir a questão do museu virtual pelo viés da noção de valor e de conservação de patrimônio. Pois, segundo o autor, a maioria dos museus virtuais, está mais preocupada em apresentar e justificar sua faceta virtual através de representações, do que utilizar as potencialidades que a Internet oferece para a interação com o visitante (LÉVY, 2000).

Nesta abordagem, diz Deloche (2000), o museu é visto como uma das soluções possíveis para um "problema colocado num campo, o do museal, isto é, o de mostrar. Museal, na definição de Deloche (2000), é o "campo problemático do "mostrar" que remete à função documental intuitiva". Porém, ainda há pouca discussão teórica sobre os museus virtuais. Segundo Weiner Schweibenz (1998) o conceito de museu virtual está em constante construção.

Por se tratar de uma temática ainda muito nova na museologia, não há um consenso em relação ao que é considerado museu virtual e o que seria apenas um site de museu. $A$ maioria dos autores que trabalha com a questão aponta para uma definição ligada à virtualização dos objetos e sua apresentação online, sem uma discussão mais aprofundada sobre os aspectos teóricos deste tipo de abordagem.

Deloche (2000) alerta que um objeto retirado de seu contexto original e colocado em outro, é a perfeita ilustração do virtual. Com relação ao virtual, Lévy (2000) complementa relacionando-o ao ciberespaço, "espaço de comunicação aberto pela interconexão mundial dos computadores e da memória dos computadores", explicando que neste ambiente esta 
sediado "o conjunto dos sistemas de comunicação eletrônicos, que transmitem informação proveniente de fontes digitais ou destinadas à digitalização" (LÉVY, 2000).

Ou seja, todo o aparato relato acima tem uma via comunicacional para repercussão: a Comunicação Científica, termo de autoria de Willian Garvey (1979), e que apresenta-se na íntegra.

A Comunicação Científica é:

[...] o Campo de estudo do espectro total de atividades informacionais que ocorrem entre os produtores da informação científica, desde o momento em que eles iniciam suas pesquisas até a publicação de seus resultados e sua aceitação e integração a um corpo de conhecimento Científico (GARVEY, 1979).

Portanto, a Comunicação Científica refere-se ao "processo comportamental" associado à criação e à comunicação de ideias entre os cientistas, tanto no âmbito interno - comunidade científica - como no âmbito externo - público em geral (LIEVROUW, 1990, p. 457).

Realiza-se baseada no modo tradicional do processo de "comunicação clássica", tal como descrito, em 1949, por Shannon e Weaver: emissor, mensagem/ canal e receptor (SHANNON, 1949). Desta maneira, ocorre através dos "canais informacionais", como por exemplo, transmitida pelo canal formal "Periódicos Científicos -- um conjunto de fontes especializadas que reúne nas edições os "Artigos Científicos"; e pelos "Trabalhos Completos em Anais de Evento Científico" -- publicação periódica referente aos atos e estudos de "Congressos Científicos", o mesmo que congressos de especialistas" (GALOÁ JOURNAL, p. 2.). E do mesmo modo comunica-se por livros editados.

São considerados como instrumentos adequados para comunicar "resultados", as "revisões e análises de pesquisas" dando espaço para a discussão entre especialistas (SANTOS, 2013, p. 2-16). Ainda, publicações e eventos deste teor são de natureza oportuna para ampliar o "conhecimento intelectual" (SANTOS, 2013, p. 2-16), "conhecimento científico" (SANTOS, 2013, p. 2-16), dando voz ao pesquisador efetivando o registro da sua contribuição e, ainda, permitindo acesso para assuntos que apontam "resolver problemas de interesse coletivo" (SANTOS, 2013, p. 2-16).

Os pesquisadores estão representados na Universidade pelos "agentes institucionais" atuantes nos Campos do Conhecimento e nomeados "locutores" no tema do poder simbólico teorizado por Bourdieu (BOURDIEU, 1989, p.23). São docentes que exercem o papel de porta-vozes (BOURDIEU, 1989, p. 23) da sua área de atuação na qual o seu capital cultural (produção) feito Patrimônio ecoa no espaço propagador da Comunicação Científica.

A classe que a pesquisa trata está representada pelo Patrimônio Científico e especificamente melhor identificado como "Patrimônio Cultural da Ciência e Tecnologia", ou "Patrimônio de C\&T" (GRANATO, 2009; p. 29) que é definido por outro pesquisador do campo da Museologia, Marcus Granato:

O Patrimônio Cultural da Ciência e Tecnologia constitui-se do legado tangível e intangível relacionado ao conhecimento científico e tecnológico produzido pela humanidade, em todas as áreas do conhecimento, que faz referência às dinâmicas científicas, de desenvolvimento tecnológico e de ensino, e à memória e ação dos indivíduosem espaços de "produção de conhecimento científico". Estes bens, em sua historicidade, podem se transformar e, de forma seletiva lhe são atribuídos valores, significados e sentidos, possibilitando sua emergência como bens de "valor cultural" (GRANATO, 2009; p. 29). 
O pesquisador Ildeu de Castro Moreira afirmar a importância que "cada um tenha a oportunidade de adquirir conhecimento sobre a ciência e seu funcionamento que lhe possibilite entender o seu entorno" (A IMPORTÂNCIA, 2014, p. 3); e neste contexto, a Comunicação Científica tem um papel relevante na formação permanente de cada pessoa e no desenvolvimento da qualificação científica.

Por outro lado, o museu virtual permite uma facilidade de exploração muito maior que os museus físicos; ele está em toda parte e sua circunferência em nenhuma, pois não tem um espaço físico, o que oferece uma liberdade de criação muito maior. O problema do acesso aos novos meios de comunicação para os museus é importante, porém não parece ter que se fazer nesses termos, isto é, substituindo o objeto por sua imagem.

Entende-se que boa parte dos museólogos e especialistas de museus ainda não está ciente da revolução que a Internet pode fazer pelos museus, talvez isso explique a falta de interesse em utilizar todas as possibilidades que a Internet oferece; além disso, muitos autores ainda veem o museu virtual como uma cópia do museu físico, ou seja, estão arraigados no conceito de museu como um espaço de exposição de determinada coleção. E isso, restringe o uso da Internet pelos museus.

A Internet trouxe para a Museologia uma nova perspectiva, porque permitiu potencializar o acesso aos museus de forma mais ampla e também por dar oportunidade aos museus de saírem de seus muros. As ações museológicas dos museus, exercidas através da Internet podem ter um alcance muito maior do que aquelas que são exercidas em seu espaço físico, pois elas podem abranger um público ainda maior.

As Unidades de Informação que sabem tirar proveito de todas as possibilidades que a Internet oferece, criando seus próprios museus virtuais, conseguem ir além de suas fronteiras. Principalmente, porque a possibilidade de uma interação maior com o público é a grande vantagem de criação de museus virtuais, sejam eles representações virtuais de museus existentes ou criados especialmente para a rede mundial de computadores.

Segundo Lima (2000), os Museus Virtuais são classificados em três categorias A-B-C, sendo a categoria $\mathrm{C}$ como representando o Museu sem correspondente no mundo físico e a coleção convertida digitalmente foi designada Museu Virtual Composição Mista, é um modelo de museu criado e existente só na web, cuja coleção exibida decorre da coleta de objetos e outros elementos que existem no mundo físico. Baseado em Lima (2000) pode-se dizer que os Museus Virtuais sob as modulações de natureza ou originais digitais, ou por conversão digital ou ainda por composição mista, referendam o motivo pelo qual se trabalha para a determinação dos usos interpretativos nos campos do conhecimento e, em se tratando da normalização terminológica, em prol da harmonização em contexto da informação e da comunicação.

De acordo com Levacov (1997), a tecnologia surge como um catalisador de mudanças, particularmente importantes e pungentes para os museus, uma vez que cria novas necessidades e altera velhos paradigmas estabelecidos ao longo de muitos séculos. A nova ordem mundial criou novas exigências na formação dos profissionais e no gerenciamento dos Museus. Segundo Lambert (2000), o papel do profissional de Museus e da Informação "antenado" com a evolução tecnológica e as mudanças ocorridas no acesso à informação no ambiente de Museus, que facilitam a vida do visitante, estará sempre baseado na utilização das novas tecnologias para atender necessidades informacionais de pesquisadores, e ainda de qualquer tipo de visitante de museus.

Os profissionais responsáveis pela gestão de museus, incluindo aqui os Museus Virtuais, devem aproximar, cada vez mais, o museu e a sua coleção/objetos dos visitantes (pre- 
sencial e/ou online) que o utilizam, fazendo com que a informação chegue aos visitantes de uma maneira mais rápida, prática e eficaz; e o Museu Virtual pode cumprir este papel de disseminador da informação.

Fato comprovado pela pesquisadora Monique Magaldi - UnB (2010), quando ela diz que as características de um Museu Virtual são: "Imaterialidade, [...], hipertextualidade, estímulo a interatividade e tendência à comunicação bi ou multidirecional". E como reforçou Rocha (2017): "Os museus virtuais podem ser uma possibilidade de minimizar as barreiras entre o patrimônio e a população, pela possibilidade de aproximação do público aos museus, desconstruindo a visão de museu como um espaço que guarda objetos antigos e espaço destinado a especialistas".

E o professor José Cláudio Oliveira (2007, p. 147) complementa:

\begin{abstract}
Os museus virtuais, sobretudo aqueles criados sem interface da instituição tradicional, deram aval à criação e informação de histórias de qualquer personagem, de objetos artísticos (de artistas renomados e iniciantes) e não-artísticos (de artistas, iniciantes e leigos), poemas e debates, tudo que compõe os acervos digitais, quebrando as barreiras do tempoespaço, dos horários de visita, da comunidade local, do silêncio e mostrando textos que partem das mais simples pessoas de um lugar qualquer.
\end{abstract}

A maioria dos autores que trabalha com a questão aponta para uma definição ligada à virtualização dos objetos e sua apresentação online, sem uma discussão mais aprofunda sobre os aspectos teóricos deste tipo de abordagem. Inclui-se nesta lista de autores que trabaIha os Museus Virtuais mais para a virtualização dos objetos, o autor Bernard Beloche, que trata da Virtualidade das obras de Arte no seu livro "Le musée virtuel: vers un éthique des nouvelles Images". O Museu Virtual, essencialmente virtual, não abre suas portas para o atendimento ao público em seu espaço físico, é o caso do Museu Virtual da Biblioteca do Instituto de Física, pois o museu não existe no mundo físico, mas sua coleção foi convertida para o mundo digital; porém nada impede que futuramente ele venha a existir fisicamente, pois as ações museológicas serão praticadas de maneiras diferentes.

\title{
3 COLEÇÃO DE CIÊNCIA E TECNOLOGIA DO IF/UFRJ TOMADA COMO OBJETOS MUSEOLÓ- GICOS
}

O Museu virtual, um serviço online, contempla Coleções de Ciência e Tecnologia do Instituto de Física (IF) como subsídio para a pesquisa científica e para a construção da História e Memória do ensino de física no Brasil e segundo Teixeira (2018, p. 183) está estruturado da seguinte forma:

Trajetória científica dos professores/fundadores do Instituto de Física da Universidade Federal do Rio de Janeiro (IF/UFRJ).

Este tópico do Museu Virtual tem como objetivo discutir as principais contribuições acadêmicas dos físicos brasileiros que fizeram parte da antiga Faculdade Nacional de Filosofia (FNFI) que posteriormente se tornou o Instituto de Física (IF/UFRJ), onde o pensamento do IF está representado pelas pesquisas elaboradas por eles ${ }^{2}$. A questão inspiradora foi a invisibilidade na literatura sobre os primórdios do Instituto de Física da Universidade Federal do Rio de Janeiro (IF/UFRJ); o que conduziu às circunstâncias em que surgiu o Instituto e co-

${ }^{2}$ Instituto de Física - UFRJ 45 anos. Rio de Janeiro: Instituto de Física, 2010. p. 10. 
mo se consolidaram os estudos nessa área, nas décadas de 1950 a 1970, período em que o Instituto foi fundado. Espera-se com esta pesquisa, detectar vestígios da trajetória e influência dos professores/fundadores na constituição do IF/UFRJ e suas aspirações enquanto pesquisadores e educadores.

Segundo Fonseca (2009), o cenário sofreu mudança significativa a partir do final dos anos 1940, quando aproveitando os efeitos do pós-guerra, com a energia nuclear alçada ao patamar de recurso estratégico das nações, cientistas brasileiros formados nos moldes dos institutos de pesquisa estrangeiros conseguiram mobilizar amplos segmentos da sociedade pela institucionalização das atividades de pesquisa no Brasil e assim começam a surgir os primeiros Institutos de Física, dentre eles o da Universidade Federal do Rio de Janeiro.

Faz-se necessário ressaltar que a presente pesquisa não se constitui em uma biografia, para tanto foi utilizado a noção de trajetória, que segundo Araújo e Fernandes (2007) pode ser "compreendida como o percurso de um indivíduo em seu campo social e as relações estabelecidas. É um estudo preliminar da trajetória dos professores/fundadores que deram aulas na antiga Faculdade Nacional de Filosofia (FNFI), e alguns deles, participaram da fundação do Instituto de Física (IF/UFRJ): Cesar Lattes, José Leite Lopes, Joaquim da Costa Ribeiro, Plínio Sussekind Rocha e Jayme Tiomno.

Mobiliário utilizado pelos pesquisadores do Instituto de Física

Foi investigado o mobiliário utilizado pelos pesquisadores do Instituto de Física, tais como: mesas, cadeiras, armários, escrivaninhas, enfim, um conjunto de móveis que faz parte da memória institucional e representa a materialização das ideias contidas na produção científica dos pesquisadores. Segundo o professor Máximo Ferreira ${ }^{3}$, está localizada na sala de reuniões do Instituto de Física, a mesa histórica utilizada pelos professores do Departamento de Física da antiga Faculdade Nacional de Filosofia (FNFI) na reunião na qual se decidiu que o Departamento de Física iria tornar-se o Instituto de Física da UFRJ. Segundo o depoimento do professor emérito Fernando de Sousa Barros, esta mesa histórica era utilizada pelo professor Cesar Lattes ${ }^{4}$.

\section{Relatórios dos pesquisadores do IF}

Segundo Hillway (1964), o relatório de pesquisa é a descrição de um estudo real que foi realizado pelo autor e sempre constitui um acréscimo de novo conhecimento. Hillway (1964), diz que a descrição do relatório exige demonstração constante de que um problema real foi estudado e resolvido, ou de que fatos novos foram descobertos. Ele tem que Inclui um relato preciso das fontes de informação pesquisadas, os métodos usados na procura e análise dos dados, a hipótese alcançada, e a evidência que fornece suporte para esta hipótese.

O relatório de pesquisa pode atuar como um veículo de informação, pois conforme Ferrez (1994) diz, ele é fonte de consulta "para a pesquisa científica e para a comunicação que, por sua vez, geram e disseminam novas informações", em vista disto, cabe tratamento sob o foco da análise que possa interpretá-lo tanto quanto à forma física que ostenta como

\footnotetext{
${ }^{3}$ Depoimento oral do Professor Máximo Ferreira (Diretor Adjunto de Desenvolvimento - IF/UFRJ em 14 de setembro de 2012.

${ }^{4}$ Depoimento oral do Professor Emérito do Departamento de Física Nuclear Fernando de Sousa Barros em 14 de setembro de 2012.
} 
o contexto histórico e social que representa, como exemplo, o caderno de laboratório que pertenceu ao pesquisador Cesar Lattes ${ }^{5}$.

Hass (1985) relata em seu livro intitulado: "Appraising the records of modern science and technology" que há uma diversidade imensa de documentos nos arquivos de instituições de pesquisa e ensino, pois os pesquisadores acumulam documentação referente às suas pesquisas, dentre eles, destaca o autor, estão as notas de leitura, sumários de cursos, exercícios de laboratório, projetos de estudantes e outros itens relacionados ao papel de um membro da faculdade. Para Haas (1985), todas essas atividades e relações profissionais resultam na criação de uma documentação crucial para o trabalho de ciência e tecnologia.

Documentos administrativos do Instituto de Física da Universidade Federal do Rio de Janeiro (UFRJ)

Os documentos administrativos são enxergados aqui no estudo como sendo: os boletins da UFRJ oficializando a instalação do Instituto de Física, as cartas, os memorandos e as atas do processo burocrático para a sua implantação. A intenção deste artigo é refletir sobre os tipos de documentos que constituem o arquivo institucional do IF/UFRJ, pois esses documentos preservam informações oficiais, reguladas por normativas, e tem como objetivo disseminar uma importante fonte de pesquisa para a história das ciências e contribuir para a reflexão sobre o conteúdo e o trabalho contido nestas fontes.

Segundo Bellotto (2002), a identificação do tipo documental depende primeiramente do reconhecimento da espécie documental, que é "a configuração que assume um documento de acordo com a disposição e a natureza das informações nele contidas", e do tipo documental, que para o autor é "a configuração que assume a espécie documental, de acordo com a atividade que a gerou" (BELLOTTO, 2002). Os documentos administrativos do IF/UFRJ também apresentam uma grande variedade de tipos de documentos que precisam ser mapeados e identificados; pois reconhecer os documentos é o ponto de partida para um trabalho de organização, preservação e acesso.

Na Biblioteca Central do Centro de Ciências Matemática e da Natureza (CCMN) encontra-se os boletins da UFRJ, oficializando a instalação do Instituto de Física. Já as cartas, memorandos e atas do processo burocrático para a implantação do Instituto está nos departamentos e na diretoria do Instituto de Física da UFRJ. Esses documentos foram digitalizados e tratados como objetos museológicos.

Ressalta-se que a documentação apresentada na pesquisa foi digitalizada e a sua salvaguarda está no ambiente digital - Museu Virtual do Instituto de Física da Universidade Federal do Rio de Janeiro IF/UFRJ.

\section{Fotografias de época do Instituto de Física e dos seus professores}

A fotografia é um documento que oferece a possibilidade de conhecer a história, do ponto de vista em que apresenta informações sobre objetos, pessoas e lugares, preservando no tempo, e está ligada a subjetividade da memória e da imaginação. Para Barthes (1980), a fotografia fornece a visão do que foi, de certa maneira, atestando a veracidade. Assim, a

\footnotetext{
${ }^{5}$ Caderno de laboratório (note book) usado por Cesar Lattes em julho de 1947. Nele, estão os cálculos que levaram à massa do méson pi depois das exposições feitas no monte Chacaltaya, na Bolívia. Depositado na Wills memorial Library, em Bristol. Essa descrição está no livro CESAR LATTES: a descoberta do méson e outras histórias. Rio de Janeiro: CBPF, 1999. p. 47.
} 
fotografia, detentora de memórias, apresenta-se como objeto de estudo e análise social e histórica.

Segundo Rodriguez (2004), a fotografia, revoluciona a memória, multiplica-a e democratiza-a, dá-lhe uma precisão e uma verdade visual, permitindo assim guardar a memória do tempo e da evolução cronológica. Pode-se dizer que ela é um instrumento de conhecimento e reconhecimento, fato comprovado por Turazzi (2006), quando diz que a escola histórica ao transformar os suportes da memória coletiva em documentos com valor de "prova" do tempo passado na história das sociedades, converteu a fotografia - mesmo sem o pretender - em "testemunho" por excelência da evolução do tempo.

As fotos de época do IF/UFRJ têm potencial científico e histórico para demonstrar um caminho possível para a preservação e difusão de coleções de Ciência e Tecnologia (C\&T). Portanto, o presente artigo buscou, por meio de estudos museológicos, identificar as relações pertinentes entre o registro fotográfico e a história/memória do Instituto de Física da Universidade Federal do Rio de Janeiro (IF/UFRJ).

Neste tópico foi dada ênfase especial às fotografias que comprovam o surgimento de atividades de pesquisa no IF/UFRJ, pois na época da FNFI, os professores realizavam essas atividades no CBPF. Um enfoque especial foi dado ao surgimento dos cursos de pósgraduação, quando as turmas foram de professores do próprio IF, pois esses professores participaram da montagem dos laboratórios de pesquisa enquanto desenvolviam suas teses.

O livro Instituto de física (2010, p. 47) descreve-se algumas fotografias localizadas, tais como: Foto da Instalação do Laboratório de Baixas Temperaturas efoto da primeira turma do mestrado em física - 1977.

\section{Instrumentos científicos utilizados nas pesquisas}

Segundo Heizer (1989) existem instrumentos científicos em universidades e museus históricos, sendo que, em alguns lugares, este material está sucateado e sem tratamento adequado; a documentação dispersa e sem o status de conservação dificulta ainda mais a ação dos pesquisadores. Para a autora é preciso reconhecer o valor desse tipo de patrimônio para que se possa dar início a reflexões e práticas mais eficientes na área de Museologia e patrimônio (HEIZER, 1989).

Segundo Loureiro (2007), a capacidade informativa de um objeto/documento jamais se esgota, portanto acredita-se que eles fornecem informações sobre eles próprios, sobre sua presença concreta e material; sobre sua trajetória que, direta ou indiretamente, podem incluir instituições, pessoas e eventos. Tem-se como exemplo o Espectrômetro ${ }^{6}$, instrumento científico utilizado pelos professores do Instituto de Física da UFRJ nas suas pesquisas na década de 1960.

Esse aparelho documenta a atividade desempenhada pelos professores do departamento de física experimental e contribuiu para um melhor conhecimento da prática científica no Brasil. Ele pertenceu ao Instituto de Física e foi doado ao Museu de Astronomia e Ciências Afins (MAST) em 20067 . Porém, ainda não foram localizados registros que identifique os

\footnotetext{
${ }^{6}$ Espectrômetro é um instrumento óptico utilizado para medir as propriedades da luz em uma determinada faixa do espectro eletromagnético, sua estrutura basicamente se resume a existência de uma rede de difração e um captador. Wikipédia. Disponível em: <http://pt.wikipedia.org/wiki/Espectr\%C3\%B4metro>. Acesso em: 27.08.2012.

7UNIVERSIDADE FEDERAL DO RIO DE JANEIRO. Termo de doação no. SP-IF 001/06.
} 
pesquisadores que utilizaram o instrumento e quais pesquisas foram resultado da sua utilização.

No livro Scientific Instruments in the History of Science: studies in transfer, use and preservation, Granato e Loureiro (2014) relatam que os Instrumentos científicos foram, de algum modo, determinantes para o desenvolvimento das instituições e da investigação a eles associada no Brasil. Granato et al. (2014) acreditam que eles congregam um conjunto de reflexões sobre o processo de musealização de objetos de ciência e tecnologia no mundo contemporâneo, mostrando como este processo resulta numa fonte para a compreensão dos métodos que envolvem as práticas científicas e os seus contextos históricos.

No Brasil, afirmam Santos e Granato (2014), parcela significativa de objetos de Ciência e Tecnologia (C\&T), com mais de 50 anos de fabricação, encontra-se abandonada em universidades e instituições de pesquisa e precisam ser localizados e musealizados.

\section{Levantamento Documental}

Tendo como parâmetro a trajetória científica dos Professores Fundadores do IF UFRJ foi realizado, também, um Levantamento Documental das suas produções científicas. Dessa forma, o levantamento pretendeu fazer um balanço das contribuições do Instituto de Física da UFRJ nesses 57 anos de existência, assim como dos docentes ligados a ele durante essa trajetória.

No âmbito da abordagem qualitativa, diversos métodos são utilizados de forma a se aproximar da realidade social, sendo o método da pesquisa documental aquele que busca compreendê-la de forma indireta por meio da análise dos inúmeros tipos de documentos produzidos pelo homem.

Nesta perspectiva, Silva (2009) acredita que a pesquisa documental permite a investigação de determinada problemática por meio do estudo dos documentos que são produzidos pelo homem e por isso revelam o seu modo de ser e compreender um fato social. Estudar documentos implica fazê-lo a partir do ponto de vista de quem os produziu. Dentro dessa perspectiva, segue uma pesquisa inicial onde consta o número de documentos recuperados em jornais e revistas:

Quadro 1: Levantamento Documental

\begin{tabular}{lccccc}
\hline TERMOS & $1960-1969$ & $1970-1979$ & $1980-1989$ & $1990-1999$ & $2000-2014$ \\
\hline Instituto de Física & 18 & 20 & 16 & 16 & 11 \\
\hline César Lattes & 102 & 27 & 14 & 17 & 12 \\
\hline José Leite Lopes & 01 & 45 & 28 & 39 & 15 \\
\hline Joaquim da Costa Ribeiro & 11 & 03 & 01 & 0 & 0 \\
\hline Plínio Sussekind Rocha & 11 & 13 & 03 & 04 & 02 \\
\hline Jayme Tiomno & 27 & 15 & 06 & 05 & 0 \\
\hline
\end{tabular}

Fonte: Biblioteca Nacional, 2020.

Após a análise dos documentos recuperados, eles foram utilizados como símbolos da importância da pesquisa realizada pelos Professores Fundadores do IF UFRJ e como testemunho do progresso da pesquisa científica brasileira na época. Segundo Chizzotti (1995, p.11), "a pesquisa investiga o mundo em que o homem vive e o próprio homem". Dessa forma, o levantamento documental pretendeu fazer um balanço das contribuições do Instituto nesses 56 anos, assim como dos docentes ligados à ele durante essa trajetória. Para tal, 
foram desenvolvidas ações de buscas de informações em jornais, feitas a partir do site da Biblioteca Nacional (BN).

\section{Produção científica (seção ainda em fase de elaboração)}

Representa a trajetória científica dos professores do IF/UFRJ, e as suas produções científicas, ou seja, símbolos da importância das pesquisas realizadas e testemunho do progresso da pesquisa científica brasileira.

Quadro 2: produção intelectual dos professores do PPG FIS IF UFRJ - ano 2020

\begin{tabular}{|c|c|c|c|c|c|c|}
\hline PROGRAMA & TíTULO & $\begin{array}{c}\text { AUTOR } \\
\text { PRINCIPAL }\end{array}$ & $\begin{array}{c}\text { TIPO DE } \\
\text { PRODUÇÃO }\end{array}$ & $\begin{array}{l}\text { SUBTIPO DE } \\
\text { PRODUÇÃOO }\end{array}$ & ANO & $\begin{array}{l}\text { PERIÓDICOS- } \\
\text { LINK }\end{array}$ \\
\hline $\begin{array}{l}\text { PPG FIS IF } \\
\text { UFRJ }\end{array}$ & $\begin{array}{l}\text { a time-dependent } \\
\text { harmonic oscillator } \\
\text { with two frequency } \\
\text { jumps: an exact } \\
\text { algebraic solution }\end{array}$ & $\begin{array}{l}\text { Carlos Au- } \\
\text { gusto Do- } \\
\text { mingues } \\
\text { Zarro }\end{array}$ & Bibliografia & $\begin{array}{l}\text { Artigo de } \\
\text { periódico }\end{array}$ & 2020 & $\begin{array}{l}\text { Brazilian- } \\
\text { journa- } \\
\text { lofphysics }\end{array}$ \\
\hline $\begin{array}{l}\text { PPG FIS IF } \\
\text { UFRJ }\end{array}$ & $\begin{array}{l}\text { a } 3 \text {-year sample of } \\
\text { almost } 1,600 \text { elves } \\
\text { recorded above } \\
\text { south america by } \\
\text { the pierre auger } \\
\text { cosmic-ray obser- } \\
\text { vatory }\end{array}$ & $\begin{array}{l}\text { Joao Ramos } \\
\text { Torres de } \\
\text { Mello Neto }\end{array}$ & Bibliografia & $\begin{array}{l}\text { Artigo de } \\
\text { periódico }\end{array}$ & 2020 & $\begin{array}{l}\text { Earth ands- } \\
\text { pacescience }\end{array}$ \\
\hline $\begin{array}{l}\text { PPG FIS IF } \\
\text { UFRJ }\end{array}$ & $\begin{array}{c}\text { absolute cross sec- } \\
\text { tions for electron } \\
\text { capture and loss of } \\
\text { o in... }\end{array}$ & $\begin{array}{l}\text { Antônio Car- } \\
\text { los Fontes } \\
\text { dos Santos }\end{array}$ & Bibliografia & $\begin{array}{l}\text { Artigo de } \\
\text { periódico }\end{array}$ & 2020 & $\begin{array}{l}\text { journal of } \\
\text { physics. con- } \\
\text { ference se- } \\
\text { ries }\end{array}$ \\
\hline
\end{tabular}

Fonte: Plataforma Sucupira Capes, 2020.

História oral dos professores eméritos e Ex-alunos do Instituto de Física da Universidade Federal do Rio de Janeiro (UFRJ).

A sociedade moderna vive em meio à tecnologia, em plena era da informação difundida pelo rádio, televisão, telefone e Internet, nos quais a oralidade se destaca nesse processo difusor da informação. Nesse sentido, para a realização desta pesquisa, foi utilizado o recurso dos depoimentos via metodologia da História Oral; foram feitas entrevistas com os professores Eméritos que graduaram-se no curso de Física da antiga Faculdade Nacional de Filosofia (FNFI) e atualmente são Professores Eméritos do Instituto de Física da UFRJ e dos atuais professores que foram Ex-alunos (graduação e pós-graduação) do Instituto de Física (IF).

Segundo o Estatuto do professor emérito da Universidade do Porto ${ }^{8}$, o termo professor emérito é um título conferido por uma entidade de ensino aos seus professores já aposentados, que atingiram alto grau de projeção no exercício de sua atividade acadêmica. Segundo o Estatuto, é concedido de forma rigorosa, àqueles profissionais que se destacaram

${ }^{8}$ Estatuto do professor emérito da Universidade do Porto (pdf). Disponível em: https://sigarra.up.pt/up/pt/conteudos_geral.ver?pct_pag_id=122231\&pct_parametros=p_pagina=122231\&pct _grupo=179\&pct_grupo=285. Acesso em: 15 dez. 2015. 
em sua área de atuação, pela relevância e/ou magnitude de sua produção e atividade científica, desfrutando de grande reconhecimento pela comunidade acadêmica9 .

Para o Centro de Pesquisa e Documentação de História Contemporânea do Brasil (CPDOC), a História Oral é uma metodologia de pesquisa que consiste em realizar entrevistas gravadas com pessoas que podem testemunhar sobre acontecimentos, conjunturas, instituições, modos de vida ou outros aspectos da história contemporânea ${ }^{10}$. Percebe-se a importância da história oral, para a pesquisa científica, quando Thompson (1992) afirma que ela pode contribuir para o resgate da memória nacional, pois segundo o autor, é necessário preservar a memória, seja ela física e/ou espacial (THOMPSON, 1992).

De acordo com Alberti (1990), a história oral pode ser empregada em pesquisas sobre temas contemporâneos, ocorridos em um passado não muito remoto, isto é, que a memória dos seres humanos alcance, para que se possa entrevistar pessoas que dele participaram, seja como atores, seja como testemunhas. Nesta etapa do estudo, foi possível colher informações que possibilitem registrar e, portanto, perpetuar impressões, vivências, lembranças dos Professores Eméritos que se dispõem a compartilhar sua memória com a coletividade e dessa forma permitir um conhecimento mais aprofundado da história e memória da fundação do Instituto de Física da Universidade Federal do Rio de Janeiro.

\section{METODOLOGIA}

A pesquisa se classifica na tipologia de uma pesquisa bibliográfica, de caráter exploratório e de teor qualiquantitativo, apoiada em fontes documentais e primárias. 0 método de pesquisa elaborado foi desenvolvimento através de uma metodologia dividida em três etapas:

- Na primeira etapa foi feito uma pesquisa iconográfica, para coletar fotografias;

- Já na segunda etapa, foi elaborado um levantamento documental, com o intuito de coletar documentos que abordavam o Instituto de Física da UFRJ e seus Professores Fundadores;

- Por fim, no tópico História oral - entrevistas- que é um tópico em fase de elaboração. A inserção no campo de pesquisa foi marcada pela consulta a fontes pessoais; por meio de entrevista-narrativa, foram ouvidos os professores Erasmo Madureira Ferreira, Fernando de Souza Barros, Herch Moysés Nussenzveig, Nelson Velho de Castro Faria, Nicim Zagury e Takeshi Kodama, todos Professores Eméritos do IF/UFRJ. Foram entrevistados também os Professores Ex-alunos do IF/UFRJ: Leandro Salazar e Máximo Ferreira da Silveira.

Para a realização desta última etapa foi necessário a elaboração de um instrumento para coleta de dados, uma carta de autorização que permite a disseminação das informações recuperadas através das entrevistas. Esta etapa da pesquisa, isto é, a coleta de dados ocorreu no período de junho a dezembro de 2018.

\section{MUSEU VIRTUAL DO IF/UFRJ: ATUALIZAÇÕES E REVISÕES}

A pesquisa enumera as atualizações e revisões elaboradas nos tópicos que compõem a ferramenta de disseminação da informação. Ou seja, a inclusão de fotos do Professor Fun-

\footnotetext{
${ }^{9}$ Idem.

${ }^{10}$ Entrevista do programa de história oral. FGV - CPDOC. Disponível em: http://cpdoc.fgv.br/acervo/historiaoral. Acesso em: 17 fev. 2016.
} 
dador e da Professora titular no tópico Fotografias; organização de conteúdo para o tópico Levantamento documental e elaboração de um termo de consentimento, denominado carta de autorização para o tópico história oral, que é composto por entrevistas com os professores eméritos e ex-alunos da Instituição.

A seguir elenca-se cada atualização/revisão efetuada no serviço online, desenvolvidos e pensados para atender de maneira satisfatória às necessidades de informação dos usuários.

Primeiro no tópico Fotografias, foram incluídas fotos e informações sobre o Professor Fundador Plínio Sussekind Rocha e da Professora Sarah de Castro Barbosa. Incluiu-se as fotos de acordo com o quadro abaixo:

Quadro 3 - Inclusão de fotos no tópico Fotografia do museu virtual do IF/UFRJ

\begin{tabular}{|c|c|c|}
\hline $\begin{array}{c}\text { TÓPICO } \\
\text { FOTOGRAFIA }\end{array}$ & IMAGEM & ENDEREÇO ELETRÔNICO \\
\hline $\begin{array}{l}\text { Plínio Sussekind } \\
\text { Rocha }\end{array}$ & $\begin{array}{l}\text { Foto do Prof. Plínio Sussekind } \\
\text { Rocha vestido para a formatura } \\
\text { dos alunos do Colégio Rivadávia } \\
\text { Correa, da qual foi paraninfo } \\
\text { (s.d.). Fonte: Acervo do Instituto } \\
\text { de Física/UFRJ. }\end{array}$ & $\begin{array}{l}\text { http://biblioteca.if.ufri.br/museu- } \\
\text { virtual/fotografias/fotografias-plinio/ }\end{array}$ \\
\hline $\begin{array}{l}\text { Plínio Sussekind } \\
\text { Rocha }\end{array}$ & $\begin{array}{l}\text { Foto do professor Plínio Sus- } \\
\text { sekind Rocha com o seu aluno de } \\
\text { graduação em Física Saulo Pereira } \\
\text { de Mello. } \\
\text { Fonte: Acervo do Instituto de } \\
\text { Física/UFRJ. }\end{array}$ & $\begin{array}{l}\text { http://biblioteca.if.ufri.br/museu- } \\
\text { virtual/fotografias/fotografias-plinio/ }\end{array}$ \\
\hline $\begin{array}{l}\text { Sarah de Castro } \\
\text { Barbosa }\end{array}$ & $\begin{array}{l}\text { Foto da Profa Sarah de Castro } \\
\text { Barbosa } \\
\text { Fonte: Acervo do Instituto de } \\
\text { Física/UFRJ. }\end{array}$ & $\begin{array}{l}\text { http://biblioteca.if.ufri.br/museu- } \\
\text { virtual/fotografias/sarah-de-castro- } \\
\text { barbosa/ }\end{array}$ \\
\hline $\begin{array}{l}\text { Sarah de Castro } \\
\text { Barbosa }\end{array}$ & $\begin{array}{l}\text { Sarah e Joaquim Pedro de Andra- } \\
\text { de em Minas Gerais. } \\
\text { Fonte: Acervo Sarah de Castro } \\
\text { Barbosa. }\end{array}$ & $\begin{array}{l}\frac{\text { http://biblioteca.if.ufri.br/museu- }}{\text { virtual/fotografias/sarah-de-castro- }} \\
\text { barbosa/ }\end{array}$ \\
\hline $\begin{array}{l}\text { Sarah de Castro } \\
\text { Barbosa }\end{array}$ & $\begin{array}{l}\text { Sarah e sua filha Alice de Andrade } \\
\text { em Arraial do Cabo. } \\
\text { Fonte: Acervo Sarah de Castro } \\
\text { Barbosa }\end{array}$ & $\begin{array}{l}\text { http://biblioteca.if.ufri.br/museu- } \\
\text { virtual/fotografias/sarah-de-castro- } \\
\text { barbosa/ }\end{array}$ \\
\hline
\end{tabular}

Fonte: Museu virtual IF-UFRJ (2020).

Para exemplificar a primeira etapa da inclusão de imagem no tópico Fotografias do Museu Virtual apresenta-se abaixo a foto do professor fundador Plínio Sussekind Rocha que participou da criação do IF-UFRJ, considerado um renomado pesquisador no campo da Física deu nome a Biblioteca do IF e foi decano do Centro de Ciências Matemáticas e da Natureza CCMN UFRJ (INSTITUTO, 2010, p. 14). Sua produção reúne dois livros publicados e participou da organização e tradução dos livros: Filosofia da ciência natural, 1981 e A ciência do século XX, 1971 = duas obras de caráter relevante no campo da Física ${ }^{11}$.

\footnotetext{
${ }^{11}$ Pesquisa nas bases de dados Web of Science e Scopus.
} 
Dotado de grande cultura e visão humanista, o professor Plínio estimulou vários jovens, alunos e alunas, tanto no ensino secundário - como ocorreu com a professora Elisa Frota Pessoa, Neusa Amato e Sarah de Castro Barbosa, mulheres pioneiras da física no Brasil - quanto na universidade (INSTITUTO, 2010, p. 18).

Figura 1. Foto do professor Plínio com o seu aluno Saulo Pereira de Mello

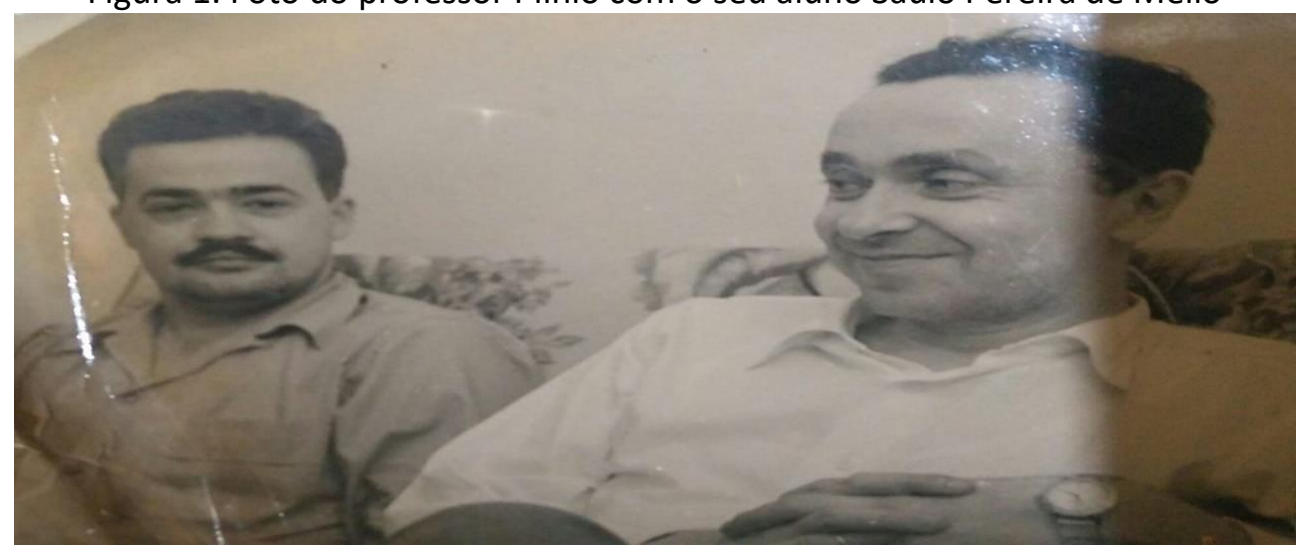

Foto: Myrce Rocha (viúva do professor Plínio Sussekind Rocha)

Já no tópico levantamento documental, que é uma coleta documental de artigos de jornais, na "Hemeroteca Digital" no site da Biblioteca Nacional; foram incluídas reportagens sobre o Instituto de Física (IF UFRJ) e dos agentes sociais (Professores Fundadores do IF UFRJ), conforme o quadro abaixo:

Quadro 4 - Inclusão de reportagens no tópico Levantamento documental do museu virtual do IF/UFRJ

\begin{tabular}{|l|l|l|l|}
\hline $\begin{array}{c}\text { TÓPICO } \\
\begin{array}{c}\text { LEVANTAMENTO } \\
\text { DOCUMENTAL }\end{array}\end{array}$ & \multicolumn{1}{|c|}{ TERMO DE BUSCA } & $\begin{array}{l}\text { PUBLICAÇÃo E } \\
\text { DATA }\end{array}$ & \multicolumn{1}{|c|}{ ENDEREÇO ELETRÔNICO } \\
\hline Instituto de Física & IF/UFRJ (2000-2014) & $\begin{array}{l}\text { Jornal do Bra- } \\
\text { sil, 18 mar. } \\
2007\end{array}$ & $\begin{array}{l}\text { http://biblioteca.if.ufrj.br/museu- } \\
\text { virtual/levantamento- } \\
\text { documental/ifufrj-2/2000-2014/ }\end{array}$ \\
\hline César Lattes & $\begin{array}{l}\text { César Lattes (1990- } \\
\text { Jornal do Bra- } \\
\text { sil, 12 maio } \\
1999\end{array}$ & $\begin{array}{l}\text { http://biblioteca.if.ufrj.br/museu- } \\
\text { virtual/levantamento- } \\
\text { documental/cesar-lattes/1990- } \\
1999 /\end{array}$ \\
\hline Jayme Tiomno & $\begin{array}{l}\text { Jayme Tiomno (1970- } \\
\text { 1979) }\end{array}$ & $\begin{array}{l}\text { Jornal do Bra- } \\
\text { sil, 06 mar. } \\
1979\end{array}$ & $\begin{array}{l}\text { http://biblioteca.if.ufrj.br/museu- } \\
\text { virtual/levantamento- } \\
\text { documental/jayme-tiomno/1970- } \\
1979 /\end{array}$ \\
\hline $\begin{array}{l}\text { Joaquim da Costa } \\
\text { Ribeiro }\end{array}$ & $\begin{array}{l}\text { Joaquim da Costa Ribei- } \\
\text { ro (1980-1989) }\end{array}$ & $\begin{array}{l}\text { Jornal do Bra- } \\
\text { sil, 21 maio } \\
1984\end{array}$ & $\begin{array}{l}\text { http://biblioteca.if.ufrj.br/museu- } \\
\text { virtual/levantamento- } \\
\text { documental/joaquim-da-costa- } \\
\text { ribeiro/1980-1989/ }\end{array}$ \\
\hline José Leite Lopes & $\begin{array}{l}\text { José Leite Lopes (1990- } \\
1999)\end{array}$ & $\begin{array}{l}\text { Jornal do Bra- } \\
\text { sil, 20 nov. } \\
1999\end{array}$ & $\begin{array}{l}\text { http://biblioteca.if.ufrj.br/museu- } \\
\text { virtual/levantamento- } \\
\text { documental/jose-leite-lopes/1990- } \\
1999 /\end{array}$ \\
\hline
\end{tabular}




\begin{tabular}{|l|l|l|l|}
\hline $\begin{array}{l}\text { Plínio Süssekind } \\
\text { Rocha }\end{array}$ & $\begin{array}{l}\text { Plínio Süssekind Rocha } \\
\text { (1990-1999) }\end{array}$ & $\begin{array}{l}\text { Jornal do Bra- } \\
\text { sil, 31 mar. } \\
1996\end{array}$ & $\begin{array}{l}\text { http://biblioteca.if.ufrj.br/museu- } \\
\text { virtual/levantamento- } \\
\text { documental/plinio-sussekind- } \\
\text { rocha/1990-1999/ }\end{array}$ \\
\hline
\end{tabular}

Fonte: Museu virtual IF-UFRJ (2020).

Por fim, no tópico História oral - entrevistas- que é um tópico em fase de elaboração foi redigida uma carta de autorização com o Termo de Assentimento elaborado pelo Comitê de Ética em Pesquisa em nome do professor entrevistado, onde ele explicita sua anuência em participar da coleta de dados para o Museu Virtual do Instituto de Física (IF) da Universidade Federal do Rio de Janeiro (UFRJ).

Logo, o entrevistado autoriza a menção do seu nome, a divulgação do áudio, da transcrição da entrevista e de fotografias no site do Museu Virtual do IF UFRJ e em outros canais de informação com o objetivo de disseminar e preservar a história e a memória da Instituição.

Quadro 5 - Carta de autorização para divulgação da entrevista tópico História oral do museu virtual do IF/UFRJ

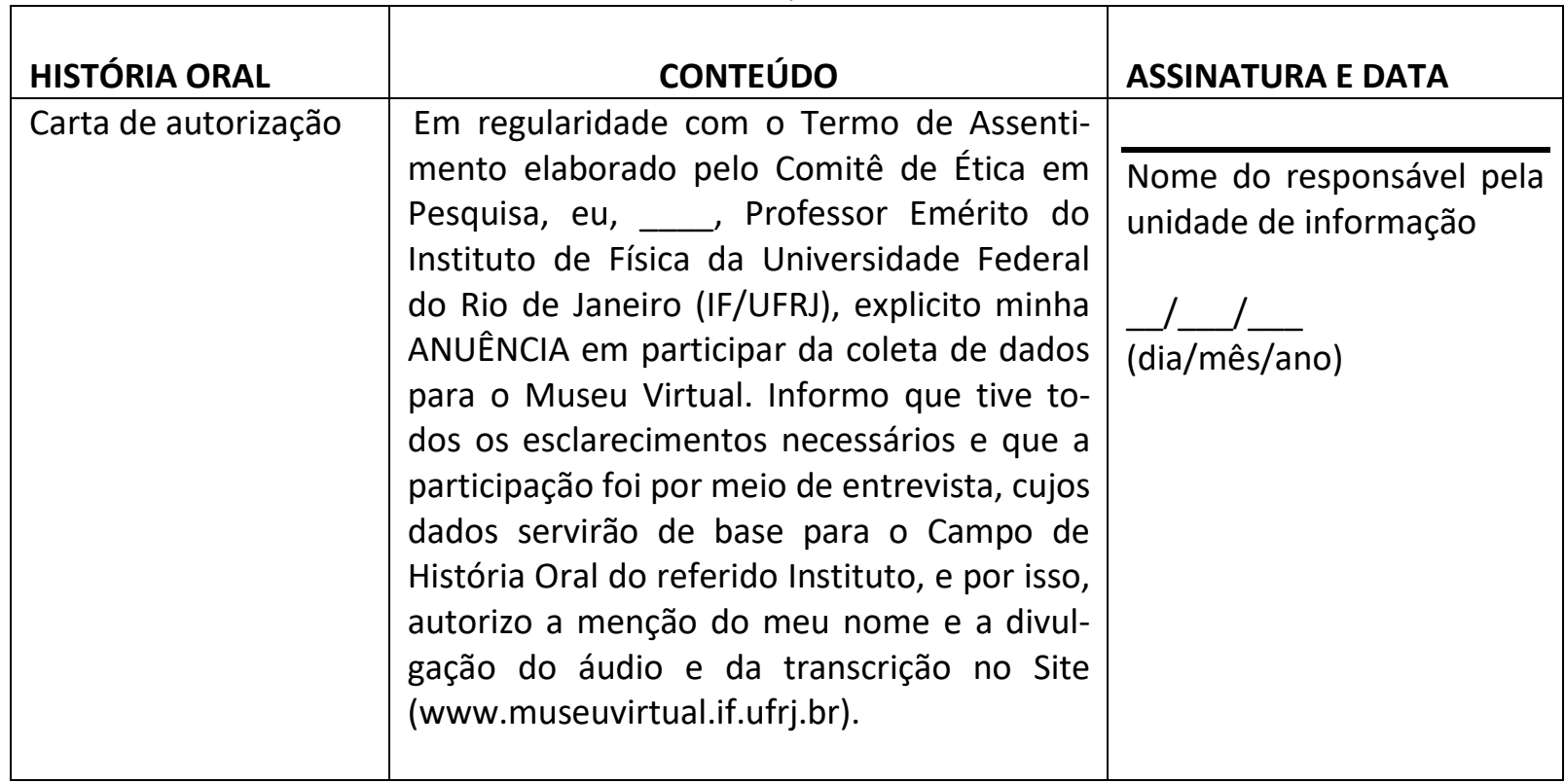

Fonte: Biblioteca do IF/UFRJ (2020).

Acentua-se que a Biblioteca do IF UFRJ é a responsável pelo Museu Virtual e detém todas as autorizações para disponibilizar as entrevistas cedidas pelos Professores Eméritos e Professores Ex-alunos.

\section{CONSIDERAÇÕES FINAIS}

Esta pesquisa se propôs elaborar atualizações e revisões nos tópicos que compõem o Museu virtual do IF UFRJ, objetivando assim enquadrá-lo como uma ferramenta de disseminação de informação em consonância com as demandas dos seus usuários. Desta forma, o presente estudo atendeu aos objetivos específicos ao incluir fotos do Professor Fundador Plínio Sussekind Rocha e da Professora Sarah de Castro Barbosa no tópico Fotografias; organizar o conteúdo para o tópico Levantamento documental e elaborar um 
termo de consentimento, denominado carta de autorização para o tópico história oral, que é composto por entrevistas com os professores eméritos e ex-alunos da Instituição.

Dentro deste contexto, pode-se afirmar que a questão elaborada para o presente artigo foi respondida; ou seja, os conteúdos do Museu virtual do IF/UFRJ que necessitavam de atualização e revisão eram os tópicos: Fotografia, Levantamento documental e História oral. Seguindo a mesma linha de raciocínio, atesta-se também que os objetivos traçados para esta pesquisa foram cumpridos, todos os tópicos do serviço online já estão atualizados e revisados, constando as modificações e de acordo com os padrões de uma ferramenta de disseminação de informação; podendo ser acessado através do link http://biblioteca.if.ufrj.br/museu-virtual/.

Salienta-se que neste primeiro momento, o Museu Virtual continua fazendo parte do site principal da Biblioteca Plínio Sussekind Rocha/Instituto de Física da Universidade Federal do Rio de Janeiro (IF/UFRJ), porém, futuramente, será um site independente, dentro da página do Instituto de Física.

Ressalta-se que há um enorme campo de trabalho para a disseminação de informação científica nas universidades públicas brasileiras, e esse trabalho é urgente, pois as novas Tecnologias da Informação e Comunicação redefiniram a forma de trabalho nas Unidades de Informação. Entretanto, destaca-se que por limitações técnicas, temporais e operacionais, houve entraves ao longo da pesquisa, tais como, a dificuldade na localização de fotografias; contato com os Professores Eméritos e Ex-alunos para entrevista e instabilidade no site da Biblioteca Nacional, fonte pesquisa para o conteúdo do tópico Levantamento Documental.

Porém, todas as fases foram cumpridas - o Museu Virtual do Instituto de Física tem o papel de disseminador da informação, fazendo com que a Biblioteca busque realizar um trabalho ligado aos interesses da comunidade científica, onde ela participa, interroga e descobre valores, além de poupar o tempo do usuário, através da otimização do serviço.

A forma tradicional de disponibilizar produtos e serviços de referência e informação ainda é largamente difundida, no entanto buscar formas virtuais para melhor atender as necessidades de informação do usuário, ainda é a forma dinamicamente mais efetiva de disponibilizar informação. Admite-se que guardar não significa dispor quando se necessita e guardar tem um custo geralmente expressivo quando da criação de sistemas que pretendem ser efetivos. Esta é justamente uma das vantagens competitivas do serviço de referência virtual, pois as fontes de informação virtuais atualizam-se rapidamente, demandam menor mão de obra e não necessitam de espaço físico para a guarda.

Os próximos passos a serem efetivados são migrar o site da Biblioteca e deixar o Museu Virtual em um site só dele; publicar as transcrições das entrevistas já realizadas e autorizadas; realizar novas entrevistas; analisar, sistematizar, tratar e divulgar a documentação em posse da instituição; criar mais conteúdo próprio (fotografias de mobiliário, instrumentos científicos e produção científica); prospectar conteúdo autorizado pelos agentes do IF (principalmente professores eméritos); buscar documentação pública de interesse da comunidade do IF e por último elaborar uma campanha de divulgação do Museu Virtual.

Por fim, como reflexão para pesquisas futuras, há a necessidade permanente de revisões e atualizações, como por exemplo: a inclusão de novos Instrumentos Científicos, Pesquisa Documental, Fotografias, Produção Científica. Para que a ferramenta esteja sempre em convergência com as necessidades dos usuários que a utilizam; porque disseminar informação sobre a pesquisa e o ensino da Física no Brasil e sua repercussão no exterior, num espaço museológico alarga horizontes e associa tais realizações às coleções materiais do 
Museu Virtual complementando a noção da interdependência do material com o imaterial representando assim a nova configuração para acervos de Museus.

\section{REFERÊNCIAS}

ALBERTI, V. História oral: a experiência do CPDOC. Rio de Janeiro: Fundação Getúlio Vargas, 1990.

ARAÚJO, M. P.; FERNANDES, T. M. O diálogo da história oral com a historiografia contemporânea. In: VISCARDI, C. M. R.; DELGADO, L. A. Ne. (org.) História Oral: Teoria, Educação e Sociedade. 1.ed. Juiz de Fora: Editora UFJF, 2007. p.13-32.

ARELLANO, M. Á. M. Serviço de referência virtual. Ci. Inf., Brasília, v. 30, n.2, p. 7-15, maio/ago. 2001.

BARTHES, Roland. La Chambre Claire, Note sur la photographie, Paris: L'Étoile, 1980. BELLOTTO, H. L. Como fazer análise diplomática e análise tipológica de documento de arquivo. São Paulo: Associação de Arquivistas de São Paulo / Arquivo do Estado, 2002 (Projeto Como Fazer, 8).

BOURDIEU, P. O poder simbólico. Tradução Fernando Tomaz. Rio de Janeiro: Bertrand Brasil, 1989. Cap. 1, 2 e 3, p.7-16.

CARVALHO, M. C. R. Bibliotecas universitárias brasileiras e a implantação de repositórios institucionais. Revista informação e universidade. v.1, n. 0, jul. 2009. Disponível em: <www.siglinux.nce.ufrj.br/.../artigomcarmen1-200911pdf>. Acesso em: 5 nov. 2012.

COSTA, I. T. M. Memória institucional: a construção conceitual numa abordagem teóricometodológica. Tese. Doutorado em Ciência da Informação (CNPq/IBICT, UFRJ/ECO). Rio de Janeiro, 1997. 169 p.

CHIZZOTTI, A. Pesquisa em ciências humanas e sociais. 2. ed. São Paulo: Cortez, 1995.

Centro de Pesquisa e Documentação de História Contemporânea do Brasil (CPDOC). O que é história oral. Disponível em:

$<$ https://cpdoc.fgv.br/acervo/historiaoral\#: :text=0\%20que\%20\%C3\%A9\%20Hist\%C3\%B3ria \%20Oral\%20\%7C\%20CPDOC\&text=A\%20hist\%C3\%B3ria\%20oral\%20\%C3\%A9\%20uma,outros \%20aspectos\%20da\%20hist\%C3\%B3ria\%20contempor\%C3\%A2nea>. Acesso em: 02 de julho 2020.

DELOCHE, B. Le musée virtuel: vers un éthique des nouvelles images. Paris: Presses Universitairesde France, 2001. p. 261 (Questions actuelles).

DESVALLÉES, A.; MAIRESSE, F. (org). Conceitos-chave de Museologia. SOARES, B. B.; CURY, M. X. (tradução e comentários). Comitê Brasileiro do Conselho Internacional de Museus: Pinacoteca do Estado de São Paulo. Secretaria de Estado da Cultura, São Paulo, 2013, p.42.Disponível em: 
<http://icom.museum/fileadmin/user_upload/pdf/Key_Concepts_of_Museology/ConceitosChavedeMuseologia_pt.pdf>. Acesso em: 19 jan. 2018.

FÁVERO, M. L. A. (coord.). Faculdade Nacional de Filosofia: o corpo docente, matizes de uma proposta autoritária. Rio de Janeiro: Universidade Federal do Rio de Janeiro; Instituto Nacional de Estudos e Pesquisas Educacionais. 1989.

FERREZ, H. D. Documentação museológica: teoria para uma boa prática. In: IPHAN. Estudos Museológicos. Rio de Janeiro: [s.n.], 1994. (Cadernos de Ensaios, 2).

FONSECA, N. L. Sobre livros, memória e identidade: uma leitura dos anos iniciais da Física e os físicos da UERJ. 2009.147f. Dissertação (Mestrado em Memória Social). Programa de Pós-Graduação em Memória Social, Universidade Federal do Estado do Rio de Janeiro, Rio de Janeiro, 2009.

GALOÁ JOURNAL- Ciencia Entrevista - Carlos Vogt e a espiral da cultura científica: da comunicação entre pares até a ampla divulgação científica para a sociedade. Disponível em: $<$ https://galoa.com.br/blog/entrevista-carlos-vogt-e-espiral-da-cultura-cientifica>. Acesso em: 19.02.2020.

GARVEY, W. D. Communication: the essence of science facilitating information among librarians, scientists, engineers and students. Oxford: Pergamon Press, 1979. 332p., p.10.

GRANATO, M. et al. Carta do patrimônio cultural de ciência e tecnologia: produção e desdobramentos. Cadernos do Patrimônio da Ciência e Tecnologia: instituições, trajetórias e valores. Disponível

em:<http://site.mast.br/hotsite_cadernos_do_patrimonio_da_ciencia_e_tecnologia/pdf/GR ANATO_RIBEIRO_ARAUJO_caderno_02_WEB_2017.pdf >. Acesso em: 10 de junho de 2019, p. 18

GRANATO, M. Panorama sobre o patrimônio de Ciência e Tecnologia no Brasil: objetos de C\&T. In.: GRANATO, Marcus; RANGEL, Marcio F. Cultura material e patrimônio de ciência e tecnologia. Rio de Janeiro: MAST, 2009; p. 29.

GRANATO, M.; LOURENÇO, M. C. (Orgs.).Scientific Instruments in the History of Science: studies in transfer, use and preservation. Rio de Janeiro: MAST, 2014.393p.

HAAS, J. K.; SAMUELS, H. W.; SIMMONS, B. T. Appraising the records of Modern Science and Technology: a guide. Massachusetts: Institute of Technology, 1985.

HEIZER, A. Observar o céu e medir a terra: instrumentos científicos e a participação do Império do Brasil na Exposição de Paris de 1989. p.165.

HILLWAY, T. Introduction to Research, 1964. pp. 256-58.

A IMPORTÂNCIA da divulgação científica. Sociedade Brasileira para o progresso da ciência (SBPC), 2014. Disponível em: 
<http://www.sbpcnet.org.br/site/noticias/materias/detalhe.php?id=2389>. Acesso em: 21 jul. 2016.

ICOM-BR. Código de ética para museus do ICOM: tópico 3, princípio. p. 18, 2009. Disponível em: <http://icom.org.br/wpcontent/themes/colorwaytheme/pdfs/codigo\%20de\%20etica/codigo_de_etica_lusofono_iii _2009.pdf>. Acesso em: 15 Fev. 2020.

INSTITUTO de física-UFRJ 45 anos. Rio de Janeiro: Instituto de Física, 2010. 56 p.

LAMBERT, M. B. M.A. O novo papel do profissional da informação na sociedade da informação. Ciência da Informação, Brasília, v. 35, n. 3, p. 125-135, set/nov. 2000.

LARA, M. L. G.; CONTI, V. L. Disseminação da informação e usuários. Perspectiva, São Paulo, v. 17, n. 3-4, p. 26-34, jul./dez. 2003. Disponível em:

<http://bdm.ufpa.br/jspui/bitstream/prefix/80/1/TCC_DisseminacaolnformacaoMeio.pdf>. Acesso em: 15 dez. 2018.

LIEVROUW, L. A.; CARLEY, M. K. Changing patterns of communication among scientistis in an era of telescience.Tecnology in Society, New York, v. 12, p. 457-477, 1990.

LEVACOV, M. Bibliotecas virtuais: (r)evolução? Ciência da Informação, Brasília, v.26, n.2, p. 125-135, mai./ago. 1997.

LIMA, D. F. C. O que se pode designar como Museu Virtual segundo os museus que assim se apresentam. In: ENANCIB 2009 - ENCONTRO NACIONAL DE PESQUISA EM CIÊNCIA DA INFORMAÇÃO, 10., 2009, João Pessoa. Anais [...] X ENANCIB, GT 9 - Museu, Patrimônio e Informação. João Pessoa: ANCIB, PPGCI-UFPB, 2009, p. 2421-2468. Disponível em: <http://enancib.ibict.br/index.php/enancib/xenancib/paper/view/3312/2438>. Acesso em: 07 jun. 2020.

LOUREIRO, M. L. N. M. Fragmentos, modelos, imagens: processos de musealização nos domínios da ciência. Datagramazero - Revista de Ciência da Informação, v. 8, n. 2, 2007.Disponível em: <http://dgz.org.br/abr07/F_I_art.htm>. Acesso em: 17 de abr. 2015.

LÉVY, P. Cibercultura. Lisboa: Instituto Piaget, 2000. p. 281.

MAGALDI, M. B.; SCHEINER, T. Reflexões sobre o Museu Virtual. In: ENANCIB 2010 - ENCONTRO NACIONAL DE PESQUISA EM CIÊNCIA DA INFORMAÇÃO, 11., 2010, Rio de Janeiro. Anais [...] X ENANCIB, GT 9 - Museu, Patrimônio e Informação. Rio de Janeiro: ANCIB, PPGCI-UFRJ, 2010, p. 1-25. Disponível em: <https://pt.scribd.com/document/343115347/MAGALDIMonique-Batista-SCHEINER-Tereza-Cristina-Reflexoes-Sobre-o-Museu-Virtual>. Acesso em: 04 dez. 2020.

MALRAUX, A. O museu imaginário. Lisboa: Edições 70, 2000. p. 245. (Arte \& Comunicação,70). 
MARTINO, L. M. S. Teoria das Mídias Digitais: linguagens, ambientes, redes. Petrópolis, RJ: Vozes, 2014.

OLIVEIRA, J. O museu digital: uma metáfora do concreto ao digital. Comunicação e Sociedade, v. 12, 2007, p. 147-161.

OTLET, P. Traité de Documentation: Le livre sur le livre. Bruxelles: Mundaneum, 1934. 452 p. Disponível em:

$<$ https://lib.ugent.be/fulltxt/handle/1854/5612/Traite_de_documentation_ocr.pdf $>$. Acesso em: 16 jun. 2020.

ROCHA, B. F. R. Conhecendo os museus virtuais e cibermuseus: aplicativo 'Fala Sério. Museologia \& Interdisciplinaridade, Brasília, v. 6, n. 11, p. 241-250, 2017 Disponível em: $<$ https://doi.org/10.26512/museologia.v6i11.17702>. Acesso em: 04 dez. 2020.

RODRIGUES, N. Álbum Família. Rio de Janeiro: Nova de Fronteira, 2004.

SANTOS, S. M.; NORONHA, D. P. Periódicos brasileiros de Ciências Sociais e Humanidades indexados na base SciELO: características formais. Perspect. ciênc. inf., Belo Horizonte , v. 18, n. 2, p. 2-16, June 2013 . Disponível em: <http://dx.doi.org/10.1590/S141399362013000200002>. Acesso em: 02 jun. 2019.

SANTOS, F. P.; GRANATO, M. Patrimônio Científico e Tecnológico no Rio deJaneiro: os objetos de C\&T nos museus cariocas. SEMINÁRIO INTERNACIONAL CULTURA MATERIAL E PATRIMÔNIO DE C\&T, 3. Anais... Rio de Janeiro: MAST, 2014.

SCHEINER, T. Apolo e Dioniso no Tempo das Musas: museu - gênese, ideia e representações na cultura ocidental. Dissertação. ECO/UFRJ, 1998.

SCHWEIBENZ, W. O Desenvolvimento dos Museus Virtuais. Icom News (Newsletter of the International Council of Museums) dedicated to Virtual Museums, v. 57, n. 3, 2004, p. 3.

SILVA, M. C. S. M. Os arquivos pessoais como fonte: reconhecendo os tipos documentais. In.: Coleção Mast: 30 anos de pesquisa. MAST/MCTI: Rio de Janeiro, 2015.

SHANNON, C. E.; WEAVER, W. The mathematical theory of communication. Urbana: Universityof Illinois Press, 1949.

STRÁNSKÝ, Z. Z. Museology as a Science (a thesis), Museologia, 15, XI, p. 33-40, 1980.

TEIXEIRA, R. S.; SOUZA, R. O. L. Avaliação da aplicabilidade de um museu virtual como ferramenta de disseminação de informação: estudo de caso no Instituto de Física da Universidade Federal do Rio de Janeiro. Ci.Inf., Brasília, DF, v.47 n.3, p.177-189, set./dez. 2018. Disponível em: <http://revista.ibict.br/ciinf/article/view/4333/3982>. Acesso em: 13 jun. 2020.

THOMPSON, P. A voz do passado. São Paulo: Paz e Terra, 1992. 
TOTA, A. L. A sociologia da arte: do museu tradicional à arte multimédia. Lisboa: Editorial Estampa, 2000. p. 2.

TURAZZI, M. I. Paisagem construída: fotografia e memória dos melhoramentos urbanos na cidade do Rio de Janeiro. Varia história, Belo Horizonte, v. 22, n. 35, p.64-78, Jan./Jun. 2006.

UNESCO. Convenção para a salvaguarda do patrimônio cultural imaterial. Paris, 2003. Disponível em: http://www.unesco.org/culture/ich/index. php?pg=00011. Acesso em: 04 de junho de 2019.

UNIVERSIDADE FEDERAL DO RIO DE JANEIRO (Brasil). Instituto de Física - UFRJ 45 anos. Rio de Janeiro: Instituto de Física, [20--]. 56 p. 